Pacific Journal of Mathematic 


\section{POINTWISE DOMINATION OF MATRICES AND COMPARISON OF $\mathscr{I}_{p}$ NORMS}

\section{BARRY SIMON}

Let $p$ be a real number in $[1, \infty)$ which is not an even integer. Let $N=2[p / 2]+5$. We give examples of $N \times N$ matrices $A$ and $B$, so that $\left|a_{i j}\right| \leqq b_{i j}$ but $\operatorname{Tr}\left(\left[A^{*} A\right]^{p / 2}\right)>$ $\operatorname{Tr}\left(\left[B^{*} B\right]^{p / 2}\right)$.

Let $A$ and $B$ be $N \times N$ matrices with

$$
\left|a_{i j}\right| \leqq b_{i j} \text {. }
$$

If we define the $p$ norm of a matrix by

$$
\|A\|_{p}=\operatorname{Tr}\left(\left[A^{*} A\right]^{p / 2}\right)^{1 / p}
$$

then it is trivial that, if $p$ is an even integer, then

$$
\|A\|_{p} \leqq\|B\|_{p}
$$

when (1) holds. For one need only write out the trace explicitly in terms of matrix elements. In a more general context, we conjectured in [5] that (1) implies (3) whenever $p \geqq 2$. The attractiveness of this conjecture is shown by the fact that I know of at least five people other than myself who have worked on proving it.

It was thus quite surprising that Peller [3] announced that (3) fails for some infinite matrices whenever $p$ is not an even integer. In correspondence, Peller described his counterexample which relies on his beautiful but elaborate theory of $\mathscr{J}_{p}$ Hankel operators (4) and on a paper of Boas (2). It follows from Peller's example that (3) must fail for some finite $N$ but it is not clear for which $N$. Our purpose here is to give explicit $N$ and to avoid the complications of Peller's $\mathscr{I}_{p}$-Hankel theory.

The idea of the construction is very simple. Boas [2] constructed polynomials $f(z), g(z)$ with $\int\left|f\left(e^{i \theta}\right)\right|^{p} d \theta>\int\left|g\left(e^{i \theta}\right)\right|^{p} d \theta$ even though the coefficients, $a_{n}$, of $f$ and coefficients, $b_{n}$, of $g$ obey $\left|a_{n}\right| \leqq b_{n}$. $a$ and $b$ should be thought of as Fourier coefficients of $f\left(e^{i \theta}\right)$ and $g\left(e^{i \theta}\right)$. It is obvious that for sufficiently large $N, \sum_{j=0}^{N-1}\left|f\left(e^{i j \theta_{N}}\right)\right|^{p} \geqq \sum_{j=0}^{N-1}\left|g\left(e^{i j \theta_{N}}\right)\right|$ where $\theta_{N}=2 \pi / N$. Again $f$ and $g$ should be viewed as functions on $Z_{N}$ and the coefficients of the polynomial (if $N$ is larger than the degrees) as $Z_{N}$-Fourier components. But the functions on $Z_{N}$ are naturally imbedded in $N \times N$ matrices in such a way $\|A\|_{p}^{p}$ is just $\sum\left|f\left(e^{i j \theta_{N}}\right)\right|^{p}$ and so that the order (1) is equivalent to the order on Fourier coefficients. 
To be explicit, given $N$ and $c_{0}, \cdots, c_{N-1}$ let $A$ be the matrix

$$
\left(\begin{array}{llllc}
c_{0} & c_{1} & \cdots & c_{N-2} & c_{N-1} \\
c_{N-1} & c_{0} & \cdots & c_{N-3} & c_{N-2} \\
c_{N-2} & c_{N-1} & \cdots & c_{N-4} & c_{N-3} \\
\vdots & & & \vdots \\
c_{1} & c_{2} & & & c_{0}
\end{array}\right)
$$

$z_{N}=\exp \left(i \theta_{N}\right)$ and let $\varphi_{j}$ be the vector with components $\left(1, z_{N}^{i}, z_{N}^{2 j}, \cdots\right.$, $\left.z_{N}^{(N-1) j}\right) ; j=0, \cdots, N-1$ and observe that

$$
A \varphi_{j}=f(j) \varphi_{j}
$$

where

$$
f(j)=\sum_{i=0}^{N-1} c_{\ell} \chi_{\ell}(j)
$$

with

$$
\chi_{\ell}(j)=z_{N}^{\ell j} .
$$

We use (6) to define $\chi_{c}$ for any integer $\iota$ although, of course, $\chi_{\iota}$ is periodic in $\ell$ with period $N$.

Of course, we have just exploited the fact that if $\sigma$ is the matrix which cyclicity permutes the coordinates by one component, then $A \sigma=\sigma A$ (indeed $A=\sum c_{p} \sigma^{k}$ ) and since $=\sigma^{N}=1, \sigma$ is naturally diagonalized in terms of the group $Z_{N}$. The $\chi$ 's are just the characters of $Z_{N}$. (In Physicist's language, since $A$ has periodic boundary conditions, one diagonalizes it in momentum space.)

Since the $\varphi_{j}$ are orthogonal vectors, $A$ is a normal operator. For such an operator $\|A\|_{p}^{p}$ is just the sum of the pth powers of the eigenvalues, i.e.,

$$
\|A\|_{p}^{p}=\sum_{j=0}^{N}|f(j)|^{p}
$$

We take

$$
\begin{gathered}
k=\left[\frac{1}{2} p\right]+2 \\
N=2 k+1=2\left[\frac{1}{2} p\right]+5 .
\end{gathered}
$$

Motivated by Boas' example, we choose

$$
c_{0}=1 ; \quad c_{1}=r ; \quad c_{k}=\lambda r_{k} ; \quad c_{\iota}=0, \quad \text { if } \ell \neq 0,1, k
$$

where $r$ is sufficiently small and 


$$
\lambda=\left(\frac{1}{2} p-1\right)\left(\frac{1}{2} p-2\right) \cdots\left(\frac{1}{2} p-k+1\right) / k ! .
$$

Notice that since $p$ is not an even integer and since $p / 2+1<k<$ $p / 2+2$, we have that $\lambda<0$. Let $d_{j}=\left|c_{j}\right|$ and let $B$ the corresponding matrix so (1) certainly holds.

We compute $\|A\|_{p}^{p}$ using (7) and the binomial theorem which is certainly legitimate if $r$ is sufficient small

where

$$
\begin{aligned}
|f(j)|^{p / 2} & =\sum_{\ell=0}^{\infty}\left(\begin{array}{c}
p / 2 \\
\ell
\end{array}\right) \sum_{m=0}^{\ell}\left(\begin{array}{c}
\ell \\
m
\end{array}\right) r^{\ell+m(k-1)} \lambda^{m} \chi_{\ell+m(k-1)}(j) \\
& =f_{1}(j)+f_{2}(j)+f_{3}(j)+0\left(r^{2 k+1}\right)
\end{aligned}
$$

$$
\begin{aligned}
& f_{1}=\sum_{\ell=0}^{k-1}\left(\begin{array}{c}
p / 2 \\
\ell
\end{array}\right) r^{\iota} \chi_{\ell} \\
& f_{2}=\sum_{\ell=k}^{2 k-1}\left[\left(\begin{array}{c}
p / 2 \\
\ell
\end{array}\right)+\lambda\left(\begin{array}{c}
p / 2 \\
\ell-k+1
\end{array}\right)\left(\begin{array}{c}
\ell-k+1 \\
1
\end{array}\right)\right] r \cdot \chi_{\ell} \\
& f_{3}=r^{2 k} \chi_{2 k}\left[\left(\begin{array}{c}
p / 2 \\
2 k
\end{array}\right)+\lambda(k+1)\left(\begin{array}{c}
p / 2 \\
k+1
\end{array}\right)+\lambda^{2}\left(\begin{array}{c}
p / 2 \\
2
\end{array}\right)\right] .
\end{aligned}
$$

Because $N=2 k+1$, the characters $\chi_{0}, \cdots, \chi_{2 k}$ are orthogonal so squaring and summing:

$$
\|A\|_{p}^{p}=\sum_{1=0}^{k-1}\left(\begin{array}{c}
p / 2 \\
j
\end{array}\right)^{2} r^{2 j}+r^{2 k}\left[\left(\begin{array}{c}
p / 2 \\
k
\end{array}\right)+\lambda\left(\begin{array}{c}
p / 2 \\
1
\end{array}\right)\right]^{2}+0\left(r^{2 k+1}\right) .
$$

The formula for $\|B\|_{p}^{p}$ is identical, except $\lambda$ is replaced by $|\lambda|=-\lambda$. But $\lambda$ is exactly chosen so that

$$
\left(\begin{array}{c}
p / 2 \\
k
\end{array}\right)-\lambda\left(\begin{array}{c}
p / 2 \\
1
\end{array}\right)=0
$$

Thus, for $r$ small, $\|A\|_{p}>\|B\|_{p}$.

It was necessary to take $N=2 k+1$ rather than just $k+1$ to avoid cross terms between the $r_{0}$ and $r^{\ell}(\ell \leqq 2 k)$ factors which have the wrong sign and only vanish because $\chi_{0}$ and $\chi_{\ell}$ are orthogonal for $\iota \leqq 2 k$.

We close this paper with a series of remarks:

(1) Peller constructs infinite matrices $A, B$ which are matrices of compact operators on $\ell_{2}$ with (1) holding, $B \in \mathscr{J}_{p}$ and $A \notin \mathscr{F}_{p}$. It is easy to get such operators from our examples as follows: normalize $A, B$ so that $\|A\|_{p}>1>\|B\|_{p} \geqq\|B\| \geqq\|A\|$. Let us view $\ell_{2}$ as the tensor algebra over $\boldsymbol{C}^{N}$, i.e., as $\boldsymbol{C} \oplus \boldsymbol{C}^{N} \oplus \boldsymbol{C}^{N^{2}} \oplus \cdots$ and let $\Gamma(A)=$ $1 \oplus A \oplus(A \otimes A) \oplus \cdots$. Then $\left|\Gamma(A)_{i j}\right| \leqq\left|\Gamma(B)_{i j}\right|$ and $\Gamma(A), \Gamma(B)$ are compact, $\Gamma(B) \in \mathscr{I}_{p}$ but $\Gamma(A) \notin \mathscr{I}_{p}$. 
(2) Given any measure space, $(M, \mu)$ with $L^{2}(M, \mu)$ infinite dimensional, we cannot have that $\|A\|_{p} \leqq c\|B\|_{p}$ for some fixed $c$ and all $A, B$ with $|(A f)(m)| \leqq(B|f|)(m)$. For one can always imbed $C^{N}$ into $L^{2}(M, \mu)$ in a way preserving $\|A\|_{p}$ norms and order (map $\left(a_{1}, \cdots, a_{n}\right)$ into $\sum a_{i} f_{2}(m)$ with $f_{i}$ multiples of characteristic functions of disjoint sets). If $\|A\|_{p} \leqq c\|B\|_{p}$ held for $L^{2}(M)$ it would hold for any $\boldsymbol{C}^{N}$. But by taking tensor products of our example one can arrange that $\|A\|_{p} /\|B\|_{p}$ is arbitrarily large. [It is interesting that this tensor product/operator theory version of Katznelson's remark (quoted in Bachelis [1]) is more natural than the function theoretic construction.]

(3) Let $N(p)$ be the smallest $N$ for which there exist matrices for which (1) holds but (3) fails. Clearly we have shown

$$
N(p) \leqq 2\left[\frac{1}{2} p\right]+5
$$

but equality is most unlikely for any $p$. Indeed for $1 \leqq p<2$, we have $N(p)=2$ since if

$$
A=\left(\begin{array}{rr}
1 & 1 \\
1 & -1
\end{array}\right) \quad B=\left(\begin{array}{ll}
1 & 1 \\
1 & 1
\end{array}\right)
$$

then $\|B\|_{p}^{p}=2^{p},\|A\|_{p}^{p}=2(\sqrt{2})^{p}>\|B\|_{p}^{p}$ if $p<2$. Moreover, we owe to $\mathrm{S}$. Friedland the following simple argument showing that $N(p) \geqq 3$ if $p>2$. If $C, D$ are positive matrices with

$$
\left|c_{i j}\right| \leqq d_{i j}
$$

then with $\mu_{j}(\cdot)=$ singular values, we trivially have

$$
\mu_{1}(C) \leqq \mu_{1}(D) ; \quad \mu_{1}(C)+\mu_{2}(C) \leqq \mu_{1}(D)+\mu_{2}(D)
$$

(since for $2 \times 2$ positive matrices $\mu_{1}(C)+\mu_{2}(C)=\operatorname{Tr}(C)$ ). By general rearrangement inequalities [5]

$$
\operatorname{Tr}\left(C^{p}\right) \leqq \operatorname{Tr}\left(D^{p}\right)
$$

for any $1 \leqq p \leqq \infty$. Given $A, B$ obeying (1) and applying this remark to $C=A^{*} A, D=B^{*} B$, we see that (3) holds for any $p \geqq 2$ if $N=2$. It would be interesting to know the precise value of $N(p)$. Two natural guesses are $[p / 2]+1$ and $2[p / 2]$.

It is a pleasure to thank V. Peller for most valuable correspondence and S. Friedland for useful discussions.

\section{REFERENCES}

1. G. F. Bachelis, On the upper and lower majorant properties in $L^{p}(G)$, Quiro. J. Math., 24 (1973), 119-128. 
2. R.P. Boas, Majorant problems for trigonometric series, J. Anal. Math., 10 (1962), $253-271$.

3. V. V. Peller, Dokl. Acad. Nauk. Math., 252 (1980), 43-47; and paper in prep.

4. - Nuclearity of Hankel operators and Hankel operators of the class $\gamma_{p}$ and projecting $\gamma_{p}$ onto the Hankel operators, Leningrad preprints.

5. B. Simon, Trace Ideals and Their Applications, Cambridge University Press, 1979.

Received December 19, 1980. Research partially supported by NSF Grant MCS-7801885. Sherman Fairchild Visiting Scholar; on leave from Departments of Mathematics and Physics, Princeton University.

California Institute of TeChNology

PASADENA, CA 91125 



\section{PACIFIC JOURNAL OF MATHEMATICS}

EDITORS

DONALD BABBITT (Managing Editor)

University of California

Los Angeles, CA 90024

Hugo RossI

University of Utah

Salt Lake City, UT 84112

C. C. MOORE and ANDREW OGG

University of California

Berkeley, CA 94720

\section{J. DugundjI}

Department of Mathematics

University of Southern California

Los Angeles, CA 90007

R. FINN and J. MILGRAM

Stanford University

Stanford, CA 94305

\section{ASSOCIATE EDITORS}
R. ARENS
E. F. BECKENBACH
B. H. NEUManN
F. WOLF
K. YoSHIDA

\section{SUPPORTING INSTITUTIONS}

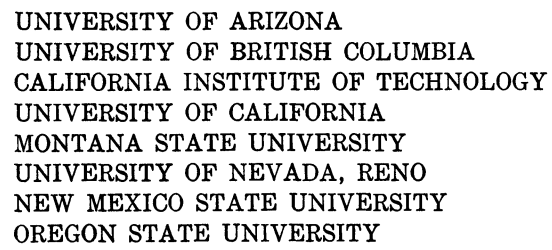

UNIVERSITY OF ARIZONA

UNIVERSITY OF BRITISH COLUMBIA

CALIFORNIA INSTITUTE OF TECHNOLOGY

UNIVERSITY OF CALIFORNIA

MONTANA STATE UNIVERSITY

UNIVERSITY OF NEVADA, RENO

NEW MEXICO STATE UNIVERSITY

OREGON STATE UNIVERSITY

\author{
UNIVERSITY OF OREGON \\ UNIVERSITY OF SOUTHERN CALIFORNIA \\ STANFORD UNIVERSITY \\ UNIVERSITY OF HAWAII \\ UNIVERSITY OF TOKYO \\ UNIVERSITY OF UTAH \\ WASHINGTON STATE UNIVERSITY \\ UNIVERSITY OF WASHINGTON
}

The Supporting Institutions listed above contribute to the cost of publication of this Journal, but they are not owners or publishers and have no responsibility for its content or policies.

Mathematical papers intended for publication in the Pacific Journal of Mathematics should be in typed form or offset-reproduced, (not dittoed), double spaced with large margins. Please do not use built up fractions in the text of the manuscript. However, you may use them in the displayed equations. Underline Greek letters in red, German in green, and script in blue. The first paragraph or two must be capable of being used separately as a synopsis of the entire paper. Please propose a heading for the odd numbered pages of less than 35 characters. Manuscripts, in triplicate, may be sent to any one of the editors. Please classify according to the scheme of Math. Reviews, Index to Vol. 39. Supply name and address of author to whom proofs should be sent. All other communications should be addressed to the managing editor, or Elaine Barth, University of California, Los Angeles, California, 90024.

50 reprints to each author are provided free for each article, only if page charges have been substantially paid. Additional copies may be obtained at cost in multiples of 50 .

The Pacific Journal of Mathematics is issued monthly as of January 1966. Regular subscription rate: $\$ 102.00$ a year (6 Vols., 12 issues). Special rate: $\$ 51.00$ a year to individual members of supporting institutions.

Subscriptions, orders for numbers issued in the last three calendar years, and changes of address shoud be sent to Pacific Journal of Mathematics, P.O. Box 969, Carmel Valley, CA 93924, U.S.A. Old back numbers obtainable from Kraus Periodicals Co., Route 100, Millwood, NY 10546.

\section{PUBLISHED BY PACIFIC JOURNAL OF MATHEMATICS, A NON-PROFIT CORPORATION}

Printed at Kokusai Bunken Insatsusha (International Academic Printing Co., Ltd.). 8-8, 3-chome, Takadanobaba, Shinjuku-ku, Tokyo 160, Japan. 


\section{Pacific Journal of Mathematics}

\section{Vol. 97, No. $2 \quad$ February, 1981}

Patrick Robert Ahern and N. V. Rao, A note on real orthogonal measures . . . . . 249

Kouhei Asano and Katsuyuki Yoshikawa, On polynomial invariants of fibered

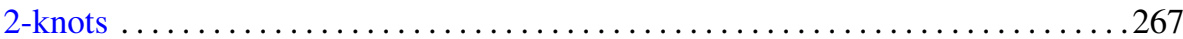

Charles A. Asmuth and Joe Repka, Tensor products for $S L_{2}(\mathscr{K})$. I.

Complementary series and the special representation

Gary Francis Birkenmeier, Baer rings and quasicontinuous rings have a

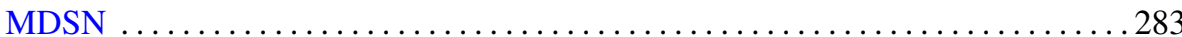

Hans-Heinrich Brungs and Günter Törner, Right chain rings and the generalized

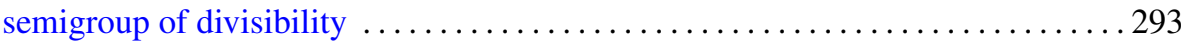

Jia-Arng Chao and Svante Janson, A note on $H^{1} q$-martingales . . . . . . . . . 307

Joseph Eugene Collison, An analogue of Kolmogorov's inequality for a class of

additive arithmetic functions

Frank Rimi DeMeyer, An action of the automorphism group of a commutative ring on its Brauer group

H. P. Dikshit and Anil Kumar, Determination of bounds similar to the Lebesgue

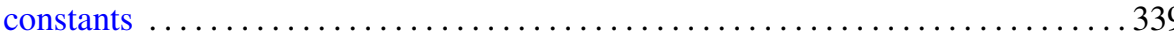

Eric Karel van Douwen, The number of subcontinua of the remainder of the plane

D. W. Dubois, Second note on Artin's solution of Hilbert's 17th problem. Order spaces

Daniel Evans Flath, A comparison of the automorphic representations of GL(3) and its twisted forms

Frederick Michael Goodman, Translation invariant closed $*$ derivations

Richard Grassl, Polynomials in denumerable indeterminates

K. F. Lai, Orders of finite algebraic groups

George Kempf, Torsion divisors on algebraic curves

Arun Kumar and D. P. Sahu, Absolute convergence fields of some triangular matrix methods

Elias Saab, On measurable projections in Banach spaces

Chao-Liang Shen, Automorphisms of dimension groups and the construction of AF algebras

Barry Simon, Pointwise domination of matrices and comparison of $\Phi_{p}$ norms

Chi-Lin Yen, A minimax inequality and its applications to variational inequalities

Stephen D. Cohen, Corrections to: "The Galois group of a polynomial with two indeterminate coefficients"

Phillip Schultz, Correction to: "The typeset and cotypeset of a rank 2 abelian group"

Pavel G. Todorov, Correction to: "New explicit formulas for the $n$th derivative of composite functions"

Douglas S. Bridges, Correction to: "On the isolation of zeroes of an analytic function" 